\section{Setting the research agenda for women and children: the role of Health Technology Assessment}

\author{
Imti Choonara, ${ }^{1}$ Tom Kenny ${ }^{2}$
}

Research is essential in that it is required to provide the scientific evidence that helps ensure patients receive the appropriate treatment. Evidence based medicine is now recognised as essential for all patients. Historically, both pregnant women and paediatric patients have been neglected by researchers. Clinical trials are more challenging in both of these patient groups. Additionally, the financial rewards for the pharmaceutical industry have been smaller due to the smaller market and need for greater formulations, especially in paediatric patients. Legislation in both the USA and the European Union has given financial incentives to the pharmaceutical industry to study medicinal products in paediatric patients. The aim of this article is to discuss how research to benefit women and children can be increased and strengthened.

\section{THE NIHR HTA PROGRAMME}

The National Institute of Health Research (NIHR) plays a key role in promoting research in the UK. Within the NIHR, the Health Technology Assessment (NIHR HTA) Programme has been in existence for 20 years. Many health professionals unfortunately are confused by the term 'technology'. A technology is a variety of interventions. It includes medicinal products but also other interventions such as diet, physiotherapy, speech therapy, surgical procedures and medical devices. The NIHR HTA Programme exists in order to compare different technologies. In some cases, this will be a direct comparison of two different technologies. In other cases, it will be a comparison of one technology against placebo.

\section{WHERE IS RESEARCH NEEDED?}

Clinical research should eventually result in improved clinical outcomes, that is, reduced mortality and morbidity for both individual patients and the

\footnotetext{
${ }^{1}$ Academic Division of Child Health, University of Nottingham, Derbyshire Children's Hospital, Derby, UK; ${ }^{2}$ National Institute for Health Research, National Evaluation Trials and Studies Coordinating Centre, University of Southampton, Southampton, UK

population as a whole. Both children and pregnant women have significantly higher mortality rates in the UK than in other Western European countries such as Sweden. WHO data for under five mortality rates in children are five per 1000 live births in the UK and only three in Sweden. ${ }^{1}$ The maternal mortality rate is three times higher in the UK than in Sweden. ${ }^{1}$ Investigator driven research is an essential part of research and has resulted in numerous clinical benefits. There are numerous funding bodies that encourage academic investigators to apply for funding in relation to their research interests. The clinical areas involved in this investigator driven research are usually those areas of research that have historically been well funded. Unfortunately, many diseases and disease areas have historically been neglected by researchers.

\section{DISABILITY-ADJUSTED LIFE YEAR}

In order to quantify the burden of disease in relation to mortality and morbidity, the metric disability-adjusted life year (DALY) is used. One DALY is equivalent to one lost year of healthy life. WHO uses DALYs in order to quantify the burden of disease. ${ }^{2}$

For women between the ages of 15 and 44 years in high income countries, mental health problems are the most significant cause of DALYs. Research into mental health issues, however, is less well funded than research into malignancies which cause fewer DALYs than mental health problems in young adult women. In children in high income countries, the main causes of DALYs are mental health problems and asthma. $^{2}$ Unfortunately, as for women, research funding for children does not correlate well with DALYs and less money is spent on research into mental health diseases than other less common conditions.

\section{COMMISSIONING RESEARCH}

In order to help ensure that research occurs in neglected areas, the NIHR HTA commissions research to fill in the gaps. Examples of such commissioned research include the use of melatonin in children with sleeping disorders and neurodevelopmental delay. ${ }^{3}$ Although melatonin did increase total sleep time by just over $20 \mathrm{~min}$, it was associated with earlier waking times. ${ }^{3}$ Melatonin significantly reduced the time taken to fall asleep. This research was initially commissioned in 2004, the clinical trial conducted between 2007 and 2011, and published in 2012. ${ }^{3}$

Another recent clinical trial evaluated the benefit of ion-exchange water softeners for the treatment of atopic eczema in children. The study involving over 300 children with eczema showed there was no objective difference in outcomes between children whose homes were fitted with a water softener and those without. ${ }^{4}$

As well as commissioning clinical trials, the NIHR HTA commissions systematic reviews and meta-analyses. A systematic review and meta-analysis evaluated the effects of dietary and lifestyle interventions in pregnancy for women who are overweight or obese on maternal and fetal weight. ${ }^{5}$ Dietary interventions were more effective than physical activity in reducing maternal gestational weight gain. ${ }^{5}$ The interventions also resulted in a significant reduction in the risk of pre-eclampsia. Additionally, there was no adverse effect on the risk of babies being born small for gestational age. The importance of this area of research is highlighted by the fact that half of the women who die during pregnancy in the UK are either obese or overweight.

\section{HOW TO SUGGEST A RESEARCH IDEA}

The NIHR HTA has recently revised its panels that review research. A Maternal, Neonatal and Child Health panel has been established with a specific focus on paediatric patients of all ages (including neonates) as well as diseases affecting women during pregnancy. The panel is keen to receive suggestions for areas of research via the NIHR HTA website (http://www.hta.ac.uk). Any individual can suggest an area of research. Additionally, special interest groups can suggest areas of research. All the proposals are reviewed and discussed. Where there is a clear need for research that is likely to benefit patients within the National Health Service (NHS), then the research proposal is commissioned, that is, the proposal is advertised and applications are invited. It is important to recognise that many research proposals are not commissioned as they represent major areas of interest for the investigator but are not determined to be of significant importance to patients within the NHS. We do hope, however, that health professionals will consider suggesting their ideas. We particularly welcome suggestions from health professionals who do not wish to carry out the research themselves but feel the research will benefit patients. 
Competing interests None.

Provenance and peer review Commissioned; externally peer reviewed.

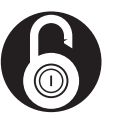

\section{OPEN ACCESS}

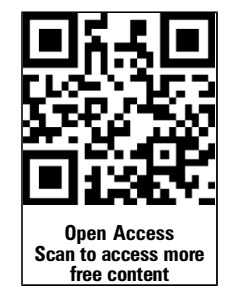

Open Access This is an Open Access article distributed in accordance with the Creative Commons Attribution Non Commercial (CC BY-NC 3.0) license, which permits others to distribute, remix, adapt, build upon this work non-commercially, and license their derivative works on different terms, provided the original work is properly cited and the use is non-commercial. See: http:// creativecommons.org/licenses/by-nc/3.0/

To cite Choonara I, Kenny T. Arch Dis Child 2013;98:573-574.

Received 14 January 2013

Revised 8 May 2013

Accepted 9 May 2013

Published Online First 7 June 2013

Arch Dis Child 2013;98:573-574

doi:10.1136/archdischild-2012-303503

\section{REFERENCES}

1 World Health Organization. World Health Statistics. 2012.
2 Modi N, Clark H, Wolfe I, et al. A healthy nation: strengthening child health research in the UK. Lancet 2013:381:73-87.

3 Gringas $\mathrm{P}$, Gamble C, Jones AP, et al.; on behalf of the MENDS Study Group. Melatonin for sleep problems in children with neurodevelopmental disorders: randomised double masked placebo controlled trial. BMJ 2012;345:e6664.

4 Thomas KS, Koller K, Dean T, et al. A multicentre randomised controlled trial and economic evaluation of ion-exchange water softeners for the treatment of eczema in children: the Softened Water Eczema Trial (SWET). Health Technol Assess 2011;15:8.

5 Thangaratinam S, Rogozinska E, Jolly K, et al. Effects of interventions in pregnancy on maternal weight and obstetric outcomes: meta-analysis of randomised evidence. BMJ 2012;344:e2088. 